taining much acid phosphatase were seen in apical region.

Cancer; It was sometimes difficult to differentiate malignant cells from normal ones. However, the most prominent feature of prostatic cancer cell was shown by nuclei which appeared in various "bizarre" shape and margination of nucleic chromatin. Numerous cytolysosomes were scattered through the cytoplasm, which seemed to be transformed from mitochondria or endoplasmic reticulum.

Acid phosphatase preparation; In normal cells, the electron dense accumulation of lead phosphate was frequently observed to be localized in the dense secreting granules. In cancer cells, lead precipitates at the dense body and cytolysosome were seen in the cytoplasm. These dense granules would be regarded as lysosome morphologically and contain acid phosphatase in it.

\title{
Histochemical and Autoradiographic Observations on Relationship between the Intracellular Glycogen Metabolism and Ribonucleic Acid Synthesis in Proliferating Cancer Cells
}

\author{
Yoshiaki IEIRI, Yukiharu SHIRAISHI and Tadao TAKEUCHI \\ Department of Pathology, Kumamoto University, School of Medicine, Kumamoto.
}

Previously, Takeuchi et al.12) stated that the enzyme system related to glycogen the the system of intracellular energy metabolism in the proliferating mechanism, instead of the liver proper function under the normal condition, and the phosphorylase activity is activated during desoxyribonucleic acid (DNA) synthesis and mitosis in the proliferating cell cycle, while the intracellular glycogen deposit decreases and disappears at the same time. This paper was concerned in the relationship between proliferating cancer cells and ribonucleic acid (RNA) synthesis.

Materials and Method: AH 13 cancer cells planted in Donryu white rats were used. The intracellular glycogen was stained by the periodic acid Shiff's reagent and it's intensity was measured with numbers of glycogen granules. The time of each phase in AH 13 cell cycle was decided by the autoradiography with ${ }^{3} \mathrm{H}$-thymidine. The RNA-synthesis was observed with ${ }^{3} \mathrm{H}$-cytidine inoculated intraperitoneally in the rat bearing tumor cells. The autoradiography was used with the stripping technique on smear materials. The intensity of the nucleic acid synthesis was calculated with numbers of silver grains.

\section{Result.}

The total replication time of $\mathrm{AH} 13$ cancer cells needed 18 hours, including 
Intensity of uptake of ${ }^{3} \mathrm{H}$-cytidine concentrated into nucleolus after the intraperitoneal injection.

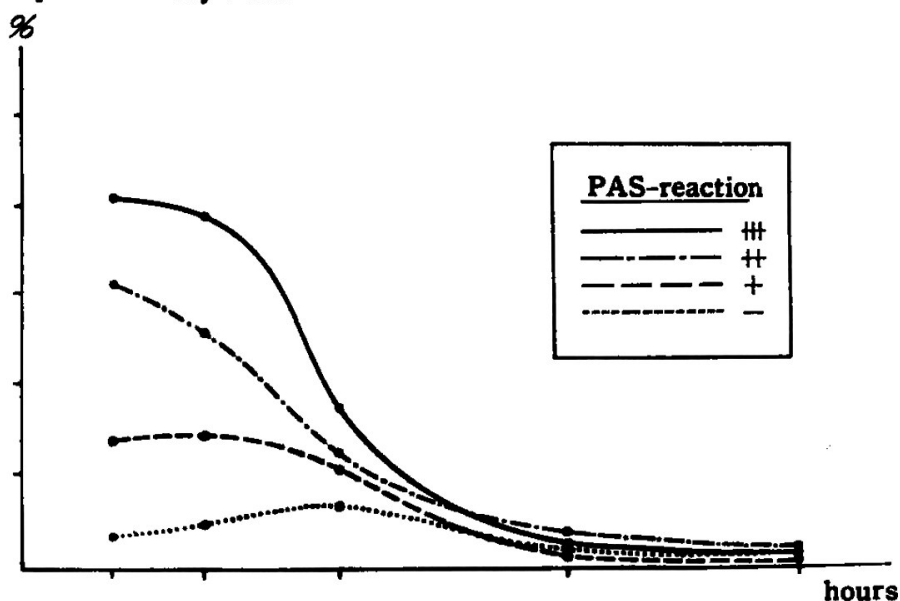

Fig. 1: Percentage of cells showing the strong uptake of ${ }^{3} \mathrm{H}$-cytidine into nucleolus.

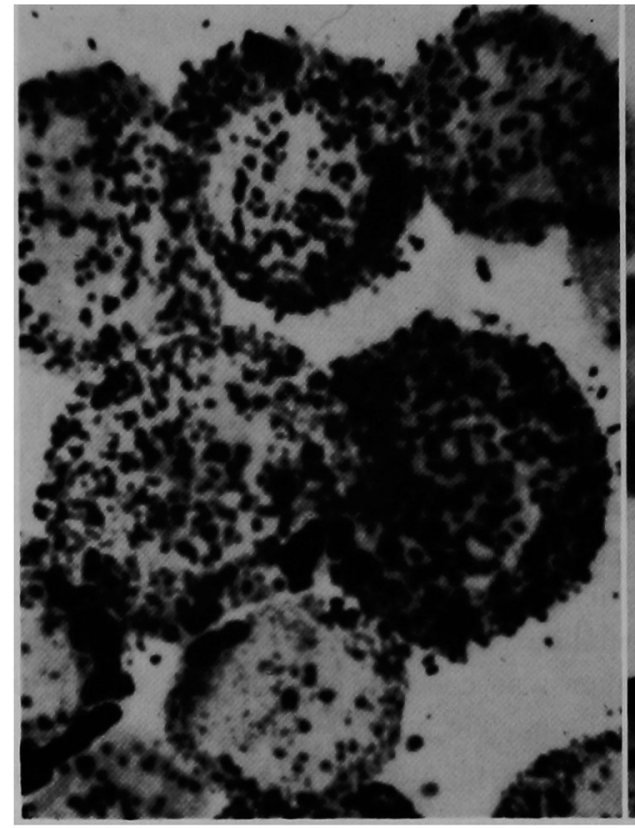

Fig. 2: The silver grains for uptake of ${ }^{3} \mathrm{H}$-cytidine are concentrated into the nuclei, particularly into the nucleoli, of the tumor cells containing richer glycogen.

(15 minutes after the intraperitoneal injection.)

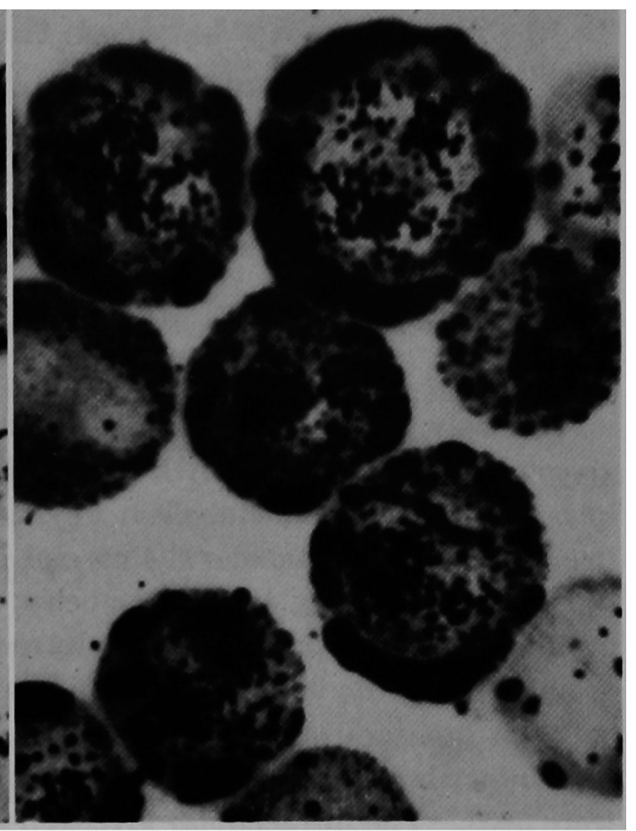

Fig. 3: The silver grains distributed in the whole cytoplasms of tumor cells in which glycogen granules have already decreased and disappeared. ( 2 hours after the intraperitoneal injection.)

8 hours in DNA-synthetic period (S), 2 hours in post-DNA synthetic preiod $\left(\mathrm{G}_{2}\right), 2$ hours in mitosis $(\mathrm{M})$, and 6 hours in pre-DNA synthetic interphase $\left(G_{1}\right)$. The cell strongly positive for the PAS reagent began to uptake ${ }^{3} \mathrm{H}-$ cytidine concentrated to the nucleolus during later half of the interphase (see 
Fig. 1, 2). Then, the uptake of ${ }^{3} \mathrm{H}$-cytidine occurred in the other nucleic regions. The silver grains concentrated in the nucleolus moved gradually releasing into the cytoplasm in the S-period, when glycogen deposit had begun to decrease (see Fig. 3). During the $\mathrm{G}_{2}$-period, ${ }^{3} \mathrm{H}$-cytidine was newly uptaken directly into whole cytoplasmic regions. During mitosis the uptake of ${ }^{3} \mathrm{H}$ cytidine did not occur and the intracellular glycogen deposit was rapidly decreased or disappeared.

The phosphorylase activity was activated in maximum at the same time. The glycogen-poor or -lacking cells began to uptake ${ }^{3} \mathrm{H}$-cytidine again directly into the cytoplasm and then the glycogen deposit was gradually increased from the peripheral zone to the central in whole cytoplasm during first half of the $\mathrm{G}_{1}$-period, when the phosphorylase activity was remarkably decreased. However, the direct uptake of ${ }^{3} \mathrm{H}$-cytidine into the cytoplasm in these periods was not always concerned with the RNA-synthesis.

\title{
Summary
}

From the experiments, it was considered that there may be a close relation between the glycogen metablism and the synthesis of ribonucleic acid in the nucleolus and it's moving to the other intracellular regions. It seemed to be, however, less than in the deoxyribonucleic acid synthesis and mitosis.

1) Takeuchi, T.; Symposia Cell. Chem. 14, 137-148, 1964. $\quad$ 2) Shiraishi, T., Ieiri, Y., Hirata, Y. \& Takeuchi, T.; (A close relation between glycogen storage and phosphorylase in tumor tissues), Proc. Histochem. Ass. Jay. 5 ; unpublished, 1965.

\section{The Study of Intestinal Alkaline Phosphatase: Radioautographic Observation of the Intestinal Absorption of L-phenylalanine}

\author{
Keiichi Watanabe and Takehiko Ohtani \\ Department of Pathology, School of Medicine, Keio University, Tokyo
}

It is a well known fact that absorptive epithelial cells of small intestine have the capacity to transport amino acids from the lumen of the intestine into their cytoplasm against a concentration gradient, and that this transport process is energy dependent and shows stereospecificity. From the kinetics of this uphill transport of amino acids, it is also confirmed that the process is enzymic nature.

In our previous study of the stereospecific inhibition of L-phenylalanine 